Research Paper

\title{
A polymorphism rs4705341 in the flanking region of miR- $143 / 145$ predicts risk and prognosis of colorectal cancer
}

\author{
Ruifen Sun ${ }^{1,2,3,4, *}$, Peng Chen ${ }^{5, *}$, Lijuan Li $^{1,5}$, Hong Sun ${ }^{1,4}$, Xinwen Nie $^{2}$, Yundan \\ Liang ${ }^{1}$, Fang Yuan ${ }^{2}$, Yan Pu${ }^{5}$, Peng Bai ${ }^{5}$, Lin Zhang ${ }^{1,2,4,5}$, Linbo Gao ${ }^{1,4}$ \\ ${ }^{1}$ Laboratory of Molecular and Translational Medicine, West China Institute of Women and Children's Health, Key Laboratory of \\ Birth Defects and Related Diseases of Women and Children (Sichuan University), Ministry of Education, West China Second \\ University Hospital, Sichuan University, Chengdu, Sichuan 610041, P.R. China \\ ${ }^{2}$ Department of Immunology, West China School of Preclinical and Forensic Medicine, Sichuan University, Chengdu, Sichuan \\ 610041 , P.R. China \\ ${ }^{3}$ Central Laboratory, Yunnan University of Chinese Traditional Medicine, Yunnan, Kunming 650500, P.R. China \\ ${ }^{4}$ Department of Obstetrics and Gynaecology, West China Second University Hospital, Sichuan University, Chengdu, Sichuan \\ 610041 , P.R. China \\ ${ }^{5}$ Department of Forensic Biology, West China School of Preclinical and Forensic Medicine, Sichuan University, Chengdu, \\ Sichuan 610041, P.R. China \\ *These authors have contributed equally to this work \\ Correspondence to: Lin Zhang, email: zhanglin@scu.edu.cn \\ Linbo Gao, email: gaolinboscu@163.com
}

Keywords: miR-143/145, polymorphism, survival, colorectal cancer

Received: January 28, $2016 \quad$ Accepted: August 08, $2016 \quad$ Published: August 19, 2016

\section{ABSTRACT}

The aim of this study was to investigate the effect of a polymorphism rs4705341 in the flanking region of miR-143/145 on the risk of colorectal cancer (CRC). The rs4705341 polymorphism was analyzed in 1002 cases and 1062 controls using a polymerase chain reaction-restriction fragment length polymorphism method. We found a significantly reduced CRC susceptibility with miR-143/145 rs4705341 in homozygote comparison (adjusted $\mathrm{OR}=0.66,95 \% \mathrm{CI}, 0.50-0.88, P=0.004$ ), dominant genetic model (adjusted $\mathrm{OR}=0.80,95 \% \mathrm{CI}, 0.67-0.96, P=0.015$ ), recessive genetic model (adjusted OR $=0.73,95 \% C I, 0.56-0.94, P=0.016$ ), and allele comparison (adjusted $O R=0.83,95 \% C I, 0.73-0.94, P=0.004$ ). Stratification analysis showed that the rs4705341 was related to differentiated status, clinical stage I-II, and patients without lymph node metastasis. Moreover, patients with rs4705341GG had a longer overall survival (adjusted $\mathrm{HR}=5.57,95 \% \mathrm{CI}, 0.95-32.68$ ). These findings indicate that the miR-143/145 rs4705341 may be used as a potential biomarker for the development and prognosis of CRC.

\section{INTRODUCTION}

Colorectal cancer (CRC) takes almost 700,000 lives every year, making it one of the most common forms of neoplasia in industrial countries [1]. As the world developing, its incidence is increasing [2]. Even though the precise molecular mechanism of CRC has still remained unclear, it has been considered to be consequence of intrinsic genetic variants that are influenced by local environmental factors [3, 4]. With advances in the recognizing of the pathophysiology and genetics of $\mathrm{CRC}$, genetic biomarkers were assumed to predict the future presence of cancer and even direct the approach to therapy [5].

MicroRNAs (miRNAs) are 19-25-nucleotides noncoding RNA molecules that can result in the degradation or repression of mRNA by sequence-specific base pairing on the 3'-untranslated regions of target mRNA [6, 7]. Recent studies have identified that genetic polymorphisms in the flanking region of miRNAs were associated with cancer susceptibility [8-24]. MiR-143 and miR-145, extensively studied miRNAs, are highly expressed in mesenchymal cells, with the function of inducing cellular differentiation $[25,26]$. In our previous work, we found 
Table 1: Characteristics of the study population

\begin{tabular}{|c|c|c|}
\hline Variables & Controls $(n=1062)$ & Patients with CRC $(n=1002)$ \\
\hline Age (years, Mean \pm SD) & $57.9( \pm 10.1)$ & $60.7( \pm 13.5)$ \\
\hline \multicolumn{3}{|l|}{ Gender $(\%)$} \\
\hline Male & $623(58.7)$ & $615(61.4)$ \\
\hline Female & $439(41.3)$ & $387(38.6)$ \\
\hline \multicolumn{3}{|l|}{ Differentiated status (\%) } \\
\hline Well-Moderately & & $564(56.3)$ \\
\hline Poorly-Undifferentiated & & $438(43.7)$ \\
\hline \multicolumn{3}{|l|}{ Clinical stage $(\%)$} \\
\hline I- II & & $584(58.3)$ \\
\hline III- IV & & $418(41.7)$ \\
\hline \multicolumn{3}{|l|}{ Lymph node metastasis $(\%)$} \\
\hline Yes & & $354(35.3)$ \\
\hline No & & $648(64.7)$ \\
\hline
\end{tabular}

CRC, colorectal cancer

$\mathrm{SD}$, standard deviation

an rs4705341 polymorphism in the flanking region of miR-143/145 (-2545bp upstream from miR-143/145) was associated with CRC risk [14]. However, the sample size is very limited. In this study, we collected more samples to confirm the result and analyzed the relationship of the rs4705341 polymorphism and outcome of CRC patients.

\section{RESULTS}

\section{Characteristics of the study population}

We conducted a large-scale case-control study including 1002 CRC patients and 1062 healthy controls. The mean age of cases and controls was 60.7 and 57.9 years, respectively. The male/female ratio was about 3:2 in both case and control group. Among the cases, 564 (56.3\%) were well-moderately differentiated CRC and 438 (43.7\%) were poorly differentiated CRC. Five hundred eighty-four (58.3\%) were stage I-II, and 418 (41.7\%) were stage III-IV. Most of the cases (64.7\%) had no lymph node metastasis (Table 1).

\section{Large-scale study confirms the association of the rs4705341 polymorphism with CRC risk}

The distribution of the rs4705341 polymorphism was consistent with the Hardy-Weinberg equilibrium in the case and control group $(P=0.09$ and 0.22$)$, indicating that we obtained representative samples of the general population. As shown in Table 2, significantly reduced CRC risk was found to be associated with GG genotype and $\mathrm{G}$ allele when compared with AA genotype and A allele (GG vs. AA: adjusted $\mathrm{OR}=0.66,95 \% \mathrm{CI}, 0.50-0.88$, $P=0.004$; G vs. A: adjusted $\mathrm{OR}=0.83,95 \% \mathrm{CI}, 0.73$ $0.94, P=0.004)$. Similarly reduced risk was also observed in a dominant model (adjusted OR $=0.80,95 \% \mathrm{CI}, 0.67$ $0.96, P=0.015$ ) and recessive model (adjusted $\mathrm{OR}=0.73$, 95\%CI, 0.56-0.94, $P=0.016)$.

Next, we divided the patients into 2 groups by differentiated status, clinical stage and lymph node metastasis. We found a significantly reduced risk in either well-moderately $\mathrm{CRC}$ patients (GG vs. AA: adjusted $\mathrm{OR}=0.66,95 \% \mathrm{CI}, 0.47-0.92, P=0.014$; $\mathrm{G}$ vs. $\mathrm{A}$ : adjusted $\mathrm{OR}=0.82,95 \% \mathrm{CI}, 0.71-0.96, P=$ 0.011 ; dominant model: adjusted $\mathrm{OR}=0.79,95 \% \mathrm{CI}$, 0.64-0.97, $P=0.03$ ) or poorly-undifferentiated CRC patients (GG vs. AA: adjusted $\mathrm{OR}=0.66,95 \% \mathrm{CI}, 0.45$ $0.96, P=0.03$; G vs. A: adjusted $\mathrm{OR}=0.83,95 \% \mathrm{CI}$, $0.70-0.98, P=0.03)$. The protective effect was also found in patients with clinical stage I-II (GG vs. AA: adjusted $\mathrm{OR}=0.60,95 \% \mathrm{CI}, 0.43-0.85, P=0.004$; $\mathrm{G}$ vs. $\mathrm{A}$ : adjusted $\mathrm{OR}=0.80,95 \% \mathrm{CI}, 0.68-0.93, P=$ 0.003 ; dominant model: adjusted $\mathrm{OR}=0.76,95 \% \mathrm{CI}$, $0.62-0.94, P=0.012$; recessive model: adjusted $\mathrm{OR}=$ $0.68,95 \% \mathrm{CI}, 0.49-0.94, P=0.016)$ but not in patients with clinical stage III-IV. Moreover, the frequencies of GG genotype and $\mathrm{G}$ allele were significantly different in patients without lymph node metastasis (GG vs. AA: adjusted $\mathrm{OR}=0.61,95 \% \mathrm{CI}, 0.44-0.84, P=0.002$; G vs. $\mathrm{A}:$ adjusted $\mathrm{OR}=0.80,95 \% \mathrm{CI}, 0.69-0.93, P=0.003$; dominant model: adjusted $\mathrm{OR}=0.77,95 \% \mathrm{CI}, 0.63-0.94$, $P=0.012$; recessive model: adjusted $\mathrm{OR}=0.69,95 \% \mathrm{CI}$, $0.51-0.94, P=0.018)$ rather than in patients with lymph node metastasis (Table 3 ). 
Table 2: Association between the rs4705341 polymorphism in the flanking region of miR-143/145 and risk of CRC

\begin{tabular}{|c|c|c|c|c|c|c|}
\hline \multirow[t]{2}{*}{ Polymorphism } & \multirow{2}{*}{$\begin{array}{c}\text { Controls } \\
(n=1062)(\%)\end{array}$} & \multirow{2}{*}{$\begin{array}{c}\text { CRC } \\
(n=1002)(\%)\end{array}$} & \multicolumn{2}{|c|}{$\begin{array}{c}\text { Logistic Regression } \\
\text { (Crude) }\end{array}$} & \multicolumn{2}{|c|}{ Logistic Regression (Adjusted) $\dagger$} \\
\hline & & & OR (95\%CI) & $P$ value & OR $(95 \% \mathrm{CI})$ & $P$ value \\
\hline AA & $381(35.9)$ & $412(41.1)$ & 1.00 (Ref) & & 1.00 (Ref) & \\
\hline $\mathrm{AG}$ & $526(49.5)$ & $480(47.9)$ & $0.84(0.70-1.02)$ & 0.07 & $0.84(0.70-1.02)$ & 0.07 \\
\hline GG & $155(14.6)$ & $110(11.0)$ & $0.66(0.50-0.87)$ & 0.003 & $0.66(0.50-0.88)$ & 0.004 \\
\hline $\begin{array}{l}\text { Dominant } \\
\text { model }\end{array}$ & & & $0.80(0.67-0.96)$ & 0.014 & $0.80(0.67-0.96)$ & 0.015 \\
\hline $\begin{array}{l}\text { Recessive } \\
\text { model }\end{array}$ & & & $0.72(0.56-0.94)$ & 0.014 & $0.73(0.56-0.94)$ & 0.016 \\
\hline A allele & $1288(60.6)$ & $1304(65.1)$ & 1.00 (Ref) & & 1.00 (Ref) & \\
\hline $\mathrm{G}$ allele & $836(39.4)$ & $700(34.9)$ & $0.83(0.73-0.94)$ & 0.003 & $0.83(0.73-0.94)$ & 0.004 \\
\hline
\end{tabular}

CRC, colorectal cancer

OR, odds ratio

$\mathrm{CI}$, confidence interval

$\uparrow$ OR was adjusted by age and gender.

Table 3: Stratified analyses of the rs4705341 polymorphism with clinical features of CRC

\begin{tabular}{|c|c|c|c|c|c|c|c|}
\hline \multirow{2}{*}{$\begin{array}{l}\text { Clinical } \\
\text { features }\end{array}$} & \multicolumn{2}{|c|}{ CRC patients (\%) } & \multirow{2}{*}{$\begin{array}{c}\text { Controls } \\
(\%)\end{array}$} & \multicolumn{2}{|c|}{ Ca I vs. Controls } & \multicolumn{2}{|c|}{ Ca II vs. Controls } \\
\hline & Ca I & Ca II & & $\begin{array}{c}\text { Adjusted OR } \\
(95 \% \mathrm{CI}) \dagger\end{array}$ & $\begin{array}{c}P \\
\text { value }\end{array}$ & $\begin{array}{c}\text { Adjusted OR } \\
(95 \% \mathrm{CI}) \dagger\end{array}$ & $\begin{array}{c}P \\
\text { value }\end{array}$ \\
\hline $\begin{array}{l}\text { Differentiated } \\
\text { status }\end{array}$ & Well-moderately & $\begin{array}{c}\text { Poorly- } \\
\text { undifferentiated }\end{array}$ & & & & & \\
\hline AA & $232(41.1)$ & $180(41.1)$ & $381(35.9)$ & 1.00 (Ref) & & 1.00 (Ref) & \\
\hline $\mathrm{AG}$ & $269(47.7)$ & $211(48.2)$ & $526(49.5)$ & $0.82(0.66-1.03)$ & 0.09 & $0.85(0.67-1.09)$ & 0.20 \\
\hline GG & $63(11.2)$ & $47(10.7)$ & $155(14.6)$ & $0.66(0.47-0.92)$ & 0.014 & $0.66(0.45-0.96)$ & 0.03 \\
\hline $\begin{array}{l}\text { Dominant } \\
\text { model }\end{array}$ & & & & $0.79(0.64-0.97)$ & 0.03 & $0.80(0.64-1.02)$ & 0.07 \\
\hline $\begin{array}{l}\text { Recessive } \\
\text { model }\end{array}$ & & & & $0.73(0.53-1.00)$ & 0.05 & $0.71(0.50-1.01)$ & 0.05 \\
\hline A allele & $733(65.0)$ & $571(65.2)$ & $1288(60.6)$ & 1.00 (Ref) & & 1.00 (Ref) & \\
\hline $\mathrm{G}$ allele & $395(35.0)$ & $305(34.8)$ & $836(39.4)$ & $0.82(0.71-0.96)$ & 0.011 & $0.83(0.70-0.98)$ & 0.03 \\
\hline Clinical stages & I-II & III-IV & & & & & \\
\hline $\mathrm{AA}$ & $248(42.5)$ & $164(39.2)$ & $381(35.9)$ & 1.00 (Ref) & & 1.00 (Ref) & \\
\hline $\mathrm{AG}$ & $276(47.3)$ & $204(48.8)$ & $526(49.5)$ & $0.81(0.65-1.01)$ & 0.06 & $0.89(0.70-1.14)$ & 0.37 \\
\hline GG & $60(10.3)$ & $50(12.0)$ & $155(14.6)$ & $0.60(0.43-0.85)$ & 0.004 & $0.75(0.52-1.08)$ & 0.11 \\
\hline $\begin{array}{l}\text { Dominant } \\
\text { model }\end{array}$ & & & & $0.76(0.62-0.94)$ & 0.012 & $0.86(0.68-1.09)$ & 0.21 \\
\hline $\begin{array}{l}\text { Recessive } \\
\text { model }\end{array}$ & & & & $0.68(0.49-0.94)$ & 0.016 & $0.80(0.57-1.12)$ & 0.19 \\
\hline
\end{tabular}

(Continued) 


\begin{tabular}{|c|c|c|c|c|c|c|c|}
\hline \multirow{2}{*}{$\begin{array}{l}\text { Clinical } \\
\text { features }\end{array}$} & \multicolumn{2}{|c|}{ CRC patients (\%) } & \multirow{2}{*}{$\begin{array}{c}\text { Controls } \\
(\%)\end{array}$} & \multicolumn{2}{|c|}{ Ca I vs. Controls } & \multicolumn{2}{|c|}{ Ca II vs. Controls } \\
\hline & Ca I & Ca II & & $\begin{array}{c}\text { Adjusted OR } \\
(95 \% \mathrm{CI}) \dagger\end{array}$ & $\begin{array}{c}P \\
\text { value }\end{array}$ & $\begin{array}{c}\text { Adjusted OR } \\
(95 \% \mathrm{CI}) \dagger\end{array}$ & $\begin{array}{c}P \\
\text { value }\end{array}$ \\
\hline A allele & $772(66.1)$ & $532(63.6)$ & $1288(60.6)$ & 1.00 (Ref) & & 1.00 (Ref) & \\
\hline G allele & $396(33.9)$ & $304(36.4)$ & $836(39.4)$ & $0.80(0.68-0.93)$ & 0.003 & $0.88(0.74-1.04)$ & 0.12 \\
\hline $\begin{array}{l}\text { Lymph node } \\
\text { metastasis }\end{array}$ & No & Yes & & & & & \\
\hline AA & $274(42.3)$ & $138(39.0)$ & $381(35.9)$ & 1.00 (Ref) & & 1.00 (Ref) & \\
\hline $\mathrm{AG}$ & $306(47.2)$ & $174(49.1)$ & $526(49.5)$ & $0.81(0.66-1.01)$ & 0.06 & $0.91(0.70-1.18)$ & 0.47 \\
\hline GG & $68(10.5)$ & $42(11.9)$ & $155(14.6)$ & $0.61(0.44-0.84)$ & 0.002 & $0.75(0.50-1.11)$ & 0.14 \\
\hline $\begin{array}{l}\text { Dominant } \\
\text { model }\end{array}$ & & & & $0.77(0.63-0.94)$ & 0.012 & $0.87(0.68-1.12)$ & 0.28 \\
\hline $\begin{array}{l}\text { Recessive } \\
\text { model }\end{array}$ & & & & $0.69(0.51-0.94)$ & 0.018 & $0.79(0.55-1.14)$ & 0.20 \\
\hline A allele & $854(65.9)$ & $450(63.6)$ & $1288(60.6)$ & 1.00 (Ref) & & 1.00 (Ref) & \\
\hline G allele & $442(34.1)$ & $258(36.4)$ & $836(39.4)$ & $0.80(0.69-0.93)$ & 0.003 & $0.87(0.73-1.04)$ & 0.12 \\
\hline
\end{tabular}

CRC, colorectal cancer

Ca I, group I of cases; Ca II, group II of cases

$\mathrm{OR}$, odds ratio

$\mathrm{CI}$, confidence interval

$\uparrow$ OR was adjusted by age and gender.

\section{The rs4705341GG genotype exhibited a better overall survival}

Log-rank test and Cox proportional hazards model were performed to examine the association of the rs4705341 with 3-year overall survival of CRC. The mean survival time in AA carriers was 22.7 months, whereas the mean survival time in AG/GG carriers was 26.6 months. Significant difference was observed between the 2 groups with a $P$ value of 0.04 (Figure 1). As shown in Table 4, the rs4705341GG genotype was significantly associated with a better survival of CRC (adjusted $\mathrm{HR}=5.57,95 \% \mathrm{CI}$, $0.95-32.68, P=0.038)$.

\section{DISCUSSION}

In this study, we confirmed an association of the rs4705341 polymorphism in the flanking region of miR$143 / 145$ with the risk of CRC in a Chinese population, with the rs $4705341 \mathrm{G}$ allele having a 0.83 -fold decreased risk of CRC. Stratification analysis revealed that the rs4705341 was related to clinical features of CRC patients. These findings indicate that the rs 4705341 polymorphism may be involved in the etiology and prognosis of CRC.

Recently, genetic variants in the flanking region of miRNA may contribute to individual's susceptibility to cancer [8-24]. An rs999885 in the promoter region of miR-106b-25 cluster had an increased risk and a protective effect on the prognosis of intermediate or advanced hepatocellular carcinoma [10, 15]. An rs 10877887 in the promoter of let-7 family had an elevated risk of lung cancer [18] and an increased death risk of hepatocellular carcinoma [11] but a reduced risk of papillary thyroid carcinoma [16]. An rs4938723 in the promoter of pri$\mathrm{miR}-34 \mathrm{~b} / \mathrm{c}$ had a decreased risk of colorectal cancer [12] and gastric cancer [19, 20], but an increased risk of hepatocellular carcinoma [13, 23], renal cell cancer [21], and nasopharyngeal carcinoma [24]. Based on this background, we hypothesized that polymorphism in the flanking region of miR-143/145 may be related to cancer risk. This hypothesis was confirmed by our previous work $[8,14]$ and findings from $\mathrm{Chu}$ et al. who found an rs4705342T $>C$ in the flanking region of miR-143 decreasing the risk of prostate cancer and the risk-associated $\mathrm{T}$ allele increasing the protein-binding affinity and reducing the luciferase activity [9]. In this study, we focused on a novel polymorphism rs4705341 in the flanking region of miR-143/145 and found that the rs $4705341 \mathrm{G}$ allele can protect against not only the development of CRC but also clinical outcome.

Several limitations should be discussed. CRC is a complex disease with multi-factors rather than 
a single factor involved. In this study, only genetic factor was taken into consideration. Further association studies investigating gene-gene and gene-environment interaction are of great importance to clarify the pathogenesis of CRC. Distribution of the rs4705341 is different in diverse ethnic groups. Only Chinese Han subjects were enrolled in this study. Therefore, the results cannot be directly extended to other ethnicities. Further investigations are warranted to validate the results in different races. Although we found that the rs4705341 polymorphism is potentially functional, the convincing mechanism is not fully provided. Further analysis of exact mechanism is needed.

In conclusion, we reported for the first time that the rs4705341 GG genotype was associated with a decreased CRC susceptibility and better outcome, suggesting that the miR-143/145 rs4705341 may be a potential biomarker for the development and prognosis of CRC.

\section{MATERIALS AND METHODS}

\section{Study subjects and samples}

CRC patients were consecutively recruited from the West China Hospital of Sichuan University, the Luoyang Central Hospital Affiliated to Zhengzhou University, and the Affiliated Hospital of North
Sichuan Medical College. Eight hundred and sixty-five paraffin-embedded tissue specimens (10 $\mu \mathrm{m}$ thickness) and 256 peripheral venous blood samples from CRC patients were collected between January 2010 and February 2015. The diagnosis of CRC was determined by histopathological analysis. Clinical information, including age, gender, differentiated status, clinical stage and lymph node metastasis, was retrieved from surgical and pathological records and summarized in Table 1. Follow-up data was obtained from telephone calls. During the same period, 1124 healthy volunteers visiting the hospital for physical examination was selected as controls. Individuals who had a self-reported history of colorectal disease or antecedents of malignancy were excluded from the control group. All the participants were unrelated Han population living in the central and western area of China. The study was conducted with the approval of the ethics committee of the hospital. All the subjects agreed to participant in the study.

\section{DNA extraction}

Genomic DNA from EDTA-anticogulated peripheral blood was extracted by using a commercial extraction kit (Bioteke, Beijing, China) and DNA from paraffin-embedded tissue sections was isolated by using a Puregene ${ }^{\circledR}$ DNA isolated kit (Qiagen, Hilden, Germany) according to the instruction manual.

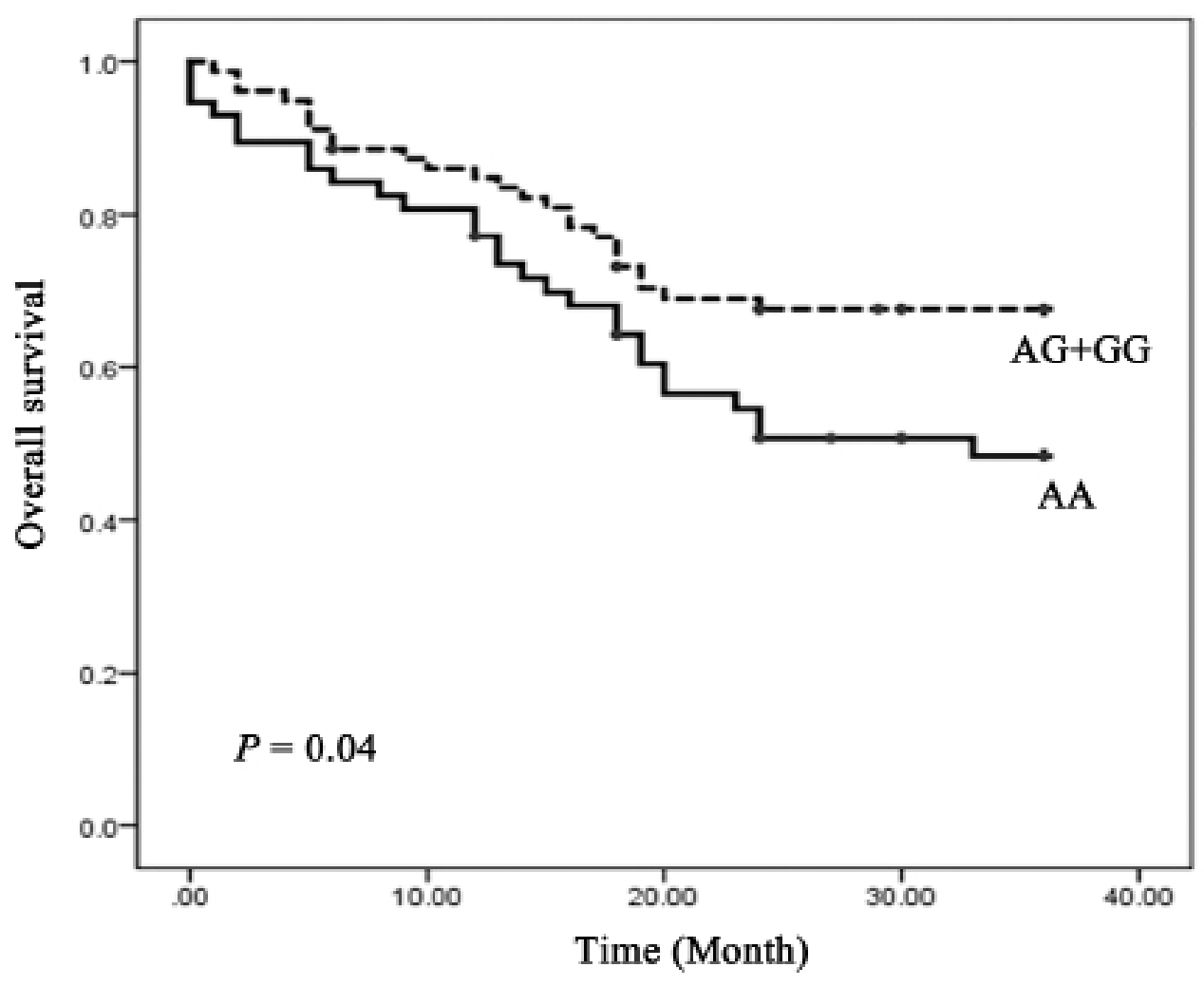

Figure 1: Kaplan-Meier overall survival curve for CRC patients by rs4705341 genotypes. 
Table 4: Association between the rs4705341 polymorphism and patient's survival

\begin{tabular}{lcccc}
\hline Polymorphism & Total $(\mathbf{n = 1 1 5})$ & Death $(\mathbf{n = 5 3 )}$ & Adjusted HR (95\%CI) $\dagger$ & $P$ value \\
\hline AA & 50 & 28 & $1.00($ Ref $)$ & 0.29 \\
AG & 55 & 23 & $1.57(0.68-3.60)$ & 0.038 \\
GG & 10 & 2 & $5.57(0.95-32.68)$ & 0.12 \\
Dominant model & & & $1.86(0.84-4.10)$ & 0.06 \\
Recessive model & & $4.54(0.82-25.03)$ & \\
\hline
\end{tabular}

$\mathrm{HR}$, hazard ratio

CI, confidence interval

$\uparrow$ HR was adjusted by age and gender.

\section{Genotyping}

The rs4705341 polymorphism was analyzed using a polymerase chain reactionrestriction fragment length polymorphism method (PCR-RFLP). The primer sequences were 5'-CCTCGGCTTCCCAAAGTGATC-3' (forward) and 5'-TCCCAGCCAGATAACTGCTTTCC-3' (reverse). PCR reaction was performed in a total volume of $10 \mu \mathrm{l}$, containing $50 \mathrm{ng}$ genomic DNA, $20 \mathrm{pM}$ each primer, and $5 \mu l$ X PCR mix (Aidlab Biotech, Beijing, China). The PCR products were digested with $\mathrm{Bcl}$ I (New England BioLabs, Beverly, MA). The rs4705341A allele was cut into two fragments of 106 and $17 \mathrm{bp}$, whereas the rs4705341G allele remained intact. For quality control, the laboratory staff performing the genotyping analysis did not know the subjects' case-control status. Two research personnel independently read the gel pictures. The samples were reanalyzed if an agreement was not reached. Moreover, the genotyping method of PCRRFLP was confirmed by sequencing (TsingKe, Chengdu, China) in $10 \%$ of all samples, and the results were all consistent. Due to DNA quality and quantity, 1062 controls and 1002 cases were genotyped successfully.

\section{Statistical analysis}

All the analyses were done using SPSS software version 13.0 (SPSS Inc, Chicago, IL). Hardy-Weinberg equilibrium was measured by $\chi^{2}$ test. The $\chi^{2}$ test, with odds ratio (OR) and respective $95 \%$ confidence interval (CI), were applied to evaluate the differences of genotype and allele distribution among cases and controls. Genotypic association tests were determined using SNPstats [27], assuming heterozygous comparison, homozygote comparison, allele comparison, dominant, and recessive genetic models. Unconditional logistic regression was used to estimate adjusted OR based on age and gender. The association between the rs4705341 polymorphism with overall survival was analyzed using Kaplan-Meier plots and the log-rank test. Cox regression analysis was performed to estimate hazard ratio (HR) and 95\%CI when controlling for age and gender. A $P$ level of $<0.05$ was considered as statistically significant.

\section{ACKNOWLEDGMENTS}

This work was supported by the National Natural Science Foundation of China (no. 81302149 and 81202387), the Ph.D. Programs Foundation of Ministry of Education of China (no. 20130181120011), Distinguished Young Scientist of Sichuan University (no. 2013SCU04A38), and the Science \& Technology Pillar Program of Sichuan Province (no. 2014KJT0592014SZ0001 and 2013JY0013).

\section{CONFLICTS OF INTEREST}

None of the authors has any potential financial conflicts of interest related to this manuscript.

\section{REFERENCES}

1. Kinzler KW, Vogelstein B. Lessons from hereditary colorectal cancer. Cell. 1996; 87:159-170.

2. Brody H. Colorectal cancer. Nature. 2015; 521:S1.

3. Carethers JM. Biomarker-directed Targeted Therapy in Colorectal Cancer. Journal of digestive cancer reports. 2015; 3:5-10.

4. Grady WM, Carethers JM. Genomic and epigenetic instability in colorectal cancer pathogenesis. Gastroenterology. 2008; 135:1079-1099.

5. Carethers JM. DNA testing and molecular screening for colon cancer. Clinical gastroenterology and hepatology. 2014; 12:377-381.

6. Bartel DP. MicroRNAs: genomics, biogenesis, mechanism, and function. Cell. 2004; 116:281-297.

7. Bartel DP. MicroRNAs: target recognition and regulatory functions. Cell. 2009; 136:215-233.

8. Liang Y, Sun R, Li L, Yuan F, Liang W, Wang L, Nie X, Chen P, Zhang L, Gao L. A Functional Polymorphism in 
the Promoter of MiR-143/145 Is Associated With the Risk of Cervical Squamous Cell Carcinoma in Chinese Women: A Case-Control Study. Medicine. 2015; 94:e1289.

9. Chu H, Zhong D, Tang J, Li J, Xue Y, Tong N, Qin C, Yin C, Zhang Z, Wang M. A functional variant in miR-143 promoter contributes to prostate cancer risk. Arch Toxicol. 2016; 90:403-414.

10. Qi F, Huang M, Pan Y, Liu Y, Liu J, Wen J, Xie K, Shen $\mathrm{H}, \mathrm{Ma} \mathrm{H}$, Miao Y, Hu Z. A genetic variant in the promoter region of miR-106b-25 cluster predict clinical outcome of HBV-related hepatocellular carcinoma in Chinese. PLoS One. 2014; 9:e85394.

11. Xie K, Liu J, Zhu L, Liu Y, Pan Y, Wen J, Ma H, Zhai $\mathrm{X}, \mathrm{Hu} \mathrm{Z}$. A potentially functional polymorphism in the promoter region of let-7 family is associated with survival of hepatocellular carcinoma. Cancer Epidemiol. 2013; 37:998-1002.

12. Gao LB, Li LJ, Pan XM, Li ZH, Liang WB, Bai P, Zhu YH, Zhang L. A genetic variant in the promoter region of miR$34 \mathrm{~b} / \mathrm{c}$ is associated with a reduced risk of colorectal cancer. Biol Chem. 2013; 394:415-420.

13. Xu Y, Liu L, Liu J, Zhang Y, Zhu J, Chen J, Liu S, Liu Z, Shi $\mathrm{H}$, Shen $\mathrm{H}, \mathrm{Hu} \mathrm{Z}$. A potentially functional polymorphism in the promoter region of $\mathrm{miR}-34 \mathrm{~b} / \mathrm{c}$ is associated with an increased risk for primary hepatocellular carcinoma. Int J Cancer. 2011; 128:412-417.

14. Li L, Pan X, Li Z, Bai P, Jin H, Wang T, Song C, Zhang L, Gao L. Association between polymorphisms in the promoter region of miR-143/145 and risk of colorectal cancer. Human immunology. 2013; 74:993-997.

15. Liu Y, Zhang Y, Wen J, Liu L, Zhai X, Liu J, Pan S, Chen $\mathrm{J}$, Shen $\mathrm{H}, \mathrm{Hu} \mathrm{Z}$. A genetic variant in the promoter region of miR-106b-25 cluster and risk of HBV infection and hepatocellular carcinoma. PLoS ONE. 2012; 7:e32230.

16. Wang Y, Wei T, Xiong J, Chen P, Wang X, Zhang L, Gao L, Zhu J. Association Between Genetic Polymorphisms in the Promoter Regions of Let-7 and Risk of Papillary Thyroid Carcinoma: A Case-Control Study. Medicine. 2015; 94:e1879.

17. Chen P, Sun R, Pu Y, Bai P, Yuan F, Liang Y, Zhou B, Wang Y, Sun Y, Zhu J, Zhang L, Gao L. Pri-Mir-34b/C and Tp-53 Polymorphisms are Associated With The Susceptibility of Papillary Thyroid Carcinoma: A Case-Control Study. Medicine. 2015; 94:e1536.
18. Shen LQ, Xie YZ, Qian XF, Zhuang ZX, Jiao Y, Qi XF. A single nucleotide polymorphism in the promoter region of let-7 family is associated with lung cancer risk in Chinese. Genet Mol Res. 2015; 14:4505-4512.

19. Pan XM, Sun RF, Li ZH, Guo XM, Qin HJ, Gao LB. Pri-miR-34b/c rs4938723 Polymorphism Is Associated with a Decreased Risk of Gastric Cancer. Genet Test Mol Biomarkers. 2015; 19:198-202.

20. Yang C, Ma X, Liu D, Wang Y, Tang R, Zhu Y, Xu Z, Yang L. Promoter polymorphisms of miR-34b/c are associated with risk of gastric cancer in a Chinese population. Tumour Biol. 2014; 35:12545-12554.

21. Zhang S, Qian J, Cao Q, Li P, Wang M, Wang J, Ju X, Meng X, Lu Q, Shao P, Zhang Z, Qin C, Yin C. A potentially functional polymorphism in the promoter region of miR$34 \mathrm{~b} / \mathrm{c}$ is associated with renal cell cancer risk in a Chinese population. Mutagenesis. 2014; 29:149-154.

22. Oh J, Kim JW, Lee BE, Jang MJ, Chong SY, Park PW, Hwang SG, Oh D, Kim NK. Polymorphisms of the pri-miR$34 \mathrm{~b} / \mathrm{c}$ promoter and TP53 codon 72 are associated with risk of colorectal cancer. Oncol Rep. 2014; 31:995-1002.

23. Son MS, Jang MJ, Jeon YJ, Kim WH, Kwon CI, Ko KH, Park PW, Hong SP, Rim KS, Kwon SW, Hwang SG, Kim NK. Promoter polymorphisms of pri-miR-34b/c are associated with hepatocellular carcinoma. Gene. 2013; 524:156-160.

24. Li L, Wu J, Sima X, Bai P, Deng W, Deng X, Zhang L, Gao L. Interactions of miR-34b/c and TP-53 polymorphisms on the risk of nasopharyngeal carcinoma. Tumour Biol. 2013; 34:1919-1923.

25. Kent OA, McCall MN, Cornish TC, Halushka MK. Lessons from miR-143/145: the importance of cell-type localization of miRNAs. Nucleic Acids Res. 2014; 42:7528-7538.

26. Chivukula RR, Shi G, Acharya A, Mills EW, Zeitels LR, Anandam JL, Abdelnaby AA, Balch GC, Mansour JC, Yopp AC, Maitra A, Mendell JT. An essential mesenchymal function for miR-143/145 in intestinal epithelial regeneration. Cell. 2014; 157:1104-1116.

27. Sole X, Guino E, Valls J, Iniesta R, Moreno V. SNPStats: a web tool for the analysis of association studies. Bioinformatics. 2006; 22:1928-1929. 